\title{
Encapsulation of Diclofenac Molecules into Poly $(\varepsilon$-Caprolactone) Electrospun Fibers for Delivery Protection
}

\author{
Loredana Tammaro, Giuseppina Russo, and Vittoria Vittoria \\ Department of Chemical and Food Engineering, University of Salerno, Via Ponte Don Melillo, 84084 Fisciano, Italy \\ Correspondence should be addressed to Vittoria Vittoria, vvittoria@unisa.it
}

Received 16 June 2009; Accepted 22 September 2009

Recommended by David Hui

$\mathrm{Mg}-\mathrm{Al}$ Hydrotalcite-like clay (LDH) intercalated with diclofenac anions (HTlc-DIC) was introduced into poly( $\varepsilon$-caprolactone) (PCL) in different concentrations by the electrospinning technique, and mats of nonwoven fibers were obtained and compared to the pristine pure electrospun PCL. The fibers, characterized by X-ray diffraction, thermogravimetric analysis, and differential scanning calorimetry, show an exfoliated clay structure up to $3 \mathrm{wt} \%$, a good thermal stability of the diclofenac molecules and a crystallinity of PCL comparable to the pure polymer. The scanning electron microscopy revealed electrospun PCL and PCL composite fibers diameters ranging between $500 \mathrm{~nm}$ to $3.0 \mu \mathrm{m}$ and a generally uniform thickness along the fibers. As the results suggested the in vitro drug release from the composite fibers is remarkably slower than the release from the corresponding control spun solutions of PCL and diclofenac sodium salt. Thus, HTlc-DIC/PCL fibrous membranes can be used as an antinflammatory scaffold for tissue engineering.

Copyright (C 2009 Loredana Tammaro et al. This is an open access article distributed under the Creative Commons Attribution License, which permits unrestricted use, distribution, and reproduction in any medium, provided the original work is properly cited.

\section{Introduction}

A challenge to the field of biomedical applications, and in particular of tissue engineering, is currently the design of synthetic matrices that can mimic the structure and biological functions of the natural extracellular matrix (ECM). Human cells can attach and organize well around fibers with suitable diameters. In this regard, nanoscale fibrous scaffolds can provide an optimal template for cells to seed, migrate, and grow. The utilization of biomaterialsboth natural and synthetic - is enabling to develop scaffolds specifically designed for many medical applications [1-8]. The production methods for preparing such devices are wide ranging, and each method has its unique characteristics. Of particular interest in tissue engineering is the creation of reproducible and biocompatible three-dimensional scaffolds resulting in biomatrix composites useful for various applications, as medical prostheses, wound dressing, and tissue template. In each specific application the ability to shape materials on different length scales, including the nanoscale, is of the utmost importance.

Recently electrospinning, able to produce nonwoven membranes of nanofibres, characterized by a high surface-to- volume ratio, has been demonstrated as a successful means of producing scaffolds having many of the desirable and controllable properties. It is applicable to a wide variety of polymers and composite polymers, both natural and synthetic. In this technique polymer nanofibers are produced from an electrostatically driven jet of polymer solution or melt. The discharged polymer solution jet undergoes a whipping process wherein the solvent evaporates and the highly stretched polymer fiber deposits on a grounded target. A number of experimental parameters control the fiber diameter and morphology. The nanofibers, with diameters ranging from microns down to hundreds of nanometers or less, can be fabricated into a variety of forms such as membranes, coatings, and films and therefore can be used in several applications [9-15].

Linear aliphatic polyesters such as polyglicolide (PGA), polylactide (PLA), polycaprolactone (PCL), as well as their copolymers, are more and more often used as the base materials for tissue engineering [16]. These materials meet several controlled release criteria; that is, they are biocompatible and biodegradable, beside they can provide high efficiency of drug loading. The release profiles of entrapped drugs can be finely tuned by controlling the degradation 
rate of the polymer matrix through molecular weight and distribution, material composition, and porosity of the carriers. However, the successful encapsulation of water soluble agents in these hydrophobic polymers still presents challenges in high drug loading and avoiding their denaturation during the formulation process. Electrospun polymer nanofibers have been designed for pharmaceutical compositions either integrating the drug and carrier materials into one kind of fiber containing both components or electrospinning the carrier material into a tubular form in which the drug particles are encapsulated. However a possible limit of these systems is a rapid release of the drug, making it available for a too short period [17, 18 .

A more remarkable innovation in this field is currently coming from nanoscience and nanotechnologies, that are opening new opportunities for producing materials with surprisingly unusual properties. The possibility to manipulate at atomic or molecular level induces structures having unique characteristics and completely new functionalities to be used not only as structural materials but also as smart structures for many fields as drug delivery. Innovative composites can be obtained employing a suitable nanoscale or other fine scale architecture to control the structural organization and, as a consequence, the physical and mechanical properties of the material. Nanoscale reinforcement has found widespread interest in the macromolecular field, since polymer properties are remarkably improved when compared with virgin polymer or conventional microcomposites. On the other hand, a wide range of additives, including biologically active molecules, can be immobilized on the inorganic lamellae with ionic bonds. They can be successively released by exchange reactions with ions present in the solutions they are put in contact.

Recently a novel therapeutic delivery system based on metal (II)-metal (III) layered double hydroxides (LDHs) or hydrotalcite-like compound (HTlc) was proposed. In our case LDHs consist of brucite-like layers of magnesium hydroxide, where some $\mathrm{Mg}(\mathrm{II})$ cations are isomorphically substituted with $\mathrm{Al}(\mathrm{III})$ cations to confer net positive charges to the layers. These charges are balanced by interlayered hydrated anions, resulting in a multilayer of alternating host layers and gallery anions [19-21]. Using ion exchange reaction, many novel complexes may be synthesized, and actually anti-inflammatory, antibiotics, plant growth regulators, and others have been incorporated into LDHs, obtaining nanohybrids that can slowly release the active molecules [22-24].

In this study we present the preparation of new fibrous composites by using electrospinning technique, obtained by fixing an anti-inflammatory drug, diclofenac sodium, into a lamellar inorganic compound, and incorporating the obtained nanohybrid into a biodegradable polycaprolactone. The structure, morphology, and thermal behavior of the electrospun fibers were analyzed. The release of the active diclofenac molecules was found much slower in comparison to the release of the fibers in which the drug was directly incorporated into the polymer.

\section{Experimental Procedures}

2.1. Materials. The Mg-Al hydrotalcite-like compound intercalated with anti-inflammatory drug, having formula $\left[\mathrm{Mg}_{0.60} \mathrm{Al}_{0.40}(\mathrm{OH})_{2}\right](\mathrm{DIC})_{0.28}\left(\mathrm{NO}_{3}\right)_{0.12} \times 1.05 \mathrm{H}_{2} \mathrm{O}$, (HTlcDIC), has been obtained according to a previously reported procedure [25-27].

Poly( $\varepsilon$-caprolactone) (PCL, $\mathrm{Mn}=80000 \mathrm{Da})$, diclofenac sodium salt (DIC-Na), and acetone were purchased from Sigma-Aldrich.

2.2. Electrospinning of PCL, PCL/HTlc-DIC, and PCL/DIC$\mathrm{Na}$ Fibers. PCL fibers were prepared by electrospinning of its solution in acetone (15 wt\% PCL). PCL/HTlc-DIC fibers with PCL/HTlc-DIC weight ratio of 90/10, 95/5, 97/3, and 99/1 were prepared by electrospinning of their mixed solution in acetone ( $15 \mathrm{wt} \%$ total polymer concentration). These solutions were prepared by first dissolving the exact amount of PCL required to obtain the fully polymer solution in acetone as the solvent. The filler HTlc-DIC was slowly added to the acetone polymer solution with vigorous stirring at $50^{\circ} \mathrm{C}$ for 3 hours. After cooling at room temperature the solutions were electrospun. Control acetone solutions were prepared as previously described with the concentration of PCL of $15 \mathrm{wt} \%$ and the concentration of DIC-Na ranging from 0.5 to $5 \mathrm{wt} \%$ respect to PCL.

Briefly, the electrospinning in a typical run was carried out as follows. PCL, PCL/HTlc-DIC, and PCL/DIC-Na solutions were placed in a glass syringe $(5 \mathrm{~mL})$ with a capillary tip diameter of $0.8 \mathrm{~mm}$. A copper wire was mounted in the spinneret and used as the positive electrode. The electrode was connected to a variable high voltage power supply purchased from Gamma High Voltage Research, Ormond, FL. The electrospinning was carried out at a constant applied voltage $(35 \mathrm{kV})$ and at a constant distance between the tip of the syringe and the collector $(20 \mathrm{~cm})$. For easy collecting of the electrospun mats, aluminum plates measuring $10 \times 10 \mathrm{~cm}$ were placed on the collection screen. The electrospun samples were placed under vacuum for 72 hours to remove any solvent residues. In the following the samples will be named as PCL-HDICn and PCL-DICNan, where $\mathrm{n}$ is the amount of HTlc-DIC and DIC-Na present in the composites, respectively.

The electrospinning conditions are summarized in Table 1.

\subsection{Methods}

Thermogravimetric Analysis (TG-DTA). Thermoanalytical characterizations were performed with a Mettler TC-10 thermobalance operating at $5^{\circ} \mathrm{C} / \mathrm{min}$ heating rate, under air flow, from $30^{\circ} \mathrm{C}$ to $1000^{\circ} \mathrm{C}$. Degradation temperature $\left(\mathrm{T}_{d}\right)$ is reported as the midpoint of the degradation step.

Differential Scanning Calorimetry (DSC). DSC measurements were carried out using a thermal analyzer Mettler DSC $822 / 400$ instrument having subambient capability at a heating rate of $10^{\circ} \mathrm{C} / \mathrm{min}$ from $-60^{\circ} \mathrm{C}$ to $180^{\circ} \mathrm{C}$. 
TABLE 1: The electrospinning conditions.

\begin{tabular}{lccccc}
\hline Sample & Solvent & $\begin{array}{c}\text { Potential } \\
(\mathrm{kV})\end{array}$ & $\begin{array}{c}\text { Distance } \\
(\mathrm{cm})\end{array}$ & $\begin{array}{c}\text { Flow rate } \\
(\mathrm{mL} / \mathrm{h})\end{array}$ & $\begin{array}{c}\text { Concentration } \\
(\mathrm{wt} \%)\end{array}$ \\
\hline PCL and all composites & Acetone & 35 & 20 & 3 & 15 \\
\hline
\end{tabular}

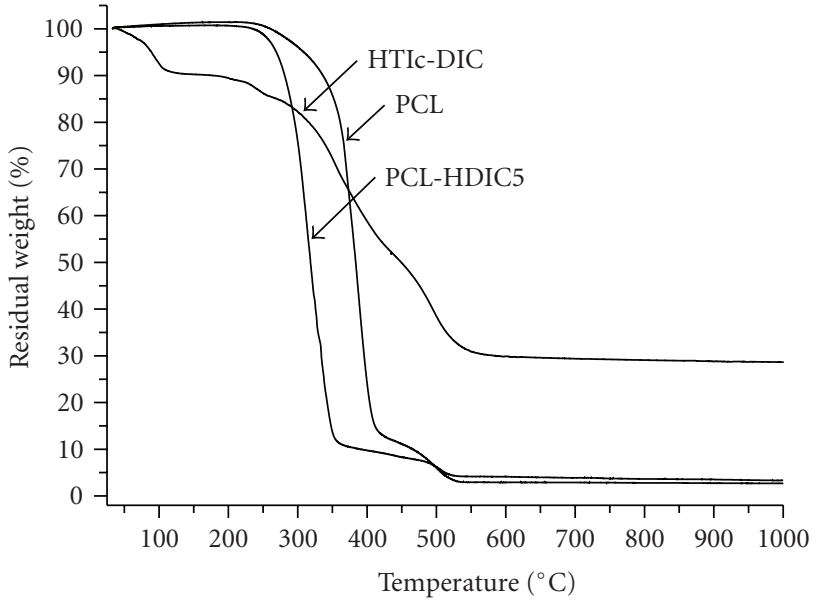

Figure 1: TG curves of the non-isothermal degradation of HTlcDIC, PCL and PCL-HDIC5. Heating rate $5^{\circ} \mathrm{C} / \mathrm{min}$, air flow.

X-Ray Powder Diffraction (XRPD). XRPD patterns were recorded, in reflection, with an automatic Bruker diffractometer (equipped with a continuous scan attachment and a proportional counter), using the nickel filtered $\mathrm{Cu} \mathrm{K \alpha}$ radiation $(\lambda=1.54050 \AA)$ and operating at $40 \mathrm{kV}$ and $40 \mathrm{~mA}$, step scan $0.05^{\circ}$ of $2 \theta$ and 3 seconds of counting time.

Scanning Electron Microscopy (SEM). All samples were sputter coated with gold, then observed by scanning electron microscope (SEM; JEOL JSM-T300).

Ultraviolet Spectroscopy (UV-VIS). In vitro drug release tests were performed using rectangular specimen of each sample, 100 micron of thickness, placed into a physiological saline solution kept in the dark $(25 \mathrm{~mL}$ of medium at room temperature and $100 \mathrm{rpm}$, three replicates). At predetermined time intervals, $2 \mathrm{~mL}$ of solution were removed and spectrophotometrically detected at $272 \mathrm{~nm}$ using a SHIMADZU UV-2401 PC spectrometer.

\section{Results and Discussion}

3.1. Thermogravimetric Analysis. The thermal behavior of all samples was evaluated by thermogravimetric analysis. Figure 1 shows the TG curves of the nanohybrid HTlc-DIC, the spun PCL and the spun PCL-HDIC5, representative of all the composites.

The content of the inorganic component (expressed as $\mathrm{g}$ of $\mathrm{MgO}$ and $\mathrm{MgAl}_{2} \mathrm{O}_{4}$ per $100 \mathrm{~g}$ of composite) and the degradation temperature have been determined by recording the thermal decomposition up to $1000^{\circ} \mathrm{C}$ in air.
Analyzing the recorded curves, we notice that the degradation occurs in different stages with various mass losses for all samples.

As for sample HTlc-DIC the first stage starts as soon as heating begins and it is completed by $150^{\circ} \mathrm{C}$, showing a $10 \%$ of the sample mass loss. This stage is associated with the dehydration of surface water molecules and the loss of crystallization water located in the interlayer region. In the next stage, between $150^{\circ} \mathrm{C}$ and $250^{\circ} \mathrm{C}$, the loss of $5 \%$ is corresponding to the thermal desorption of diclofenac anions taken up on the surface of the microcrystals. Between $250^{\circ} \mathrm{C}$ and $600^{\circ} \mathrm{C}$ there is the thermal decomposition of the organic compound, accounting for $56 \%$ of the sample mass loss. Over $800^{\circ} \mathrm{C}$ there is no change in weight loss indicating the formation of pure inorganic oxides (i.e., $\mathrm{MgO}$ and $\mathrm{MgAl}_{2} \mathrm{O}_{4}$ ). The amount of inorganic component in the sample HTlc-DIC, evaluated as oxides, is about $29 \%$, quite in agreement with that calculated from the stoichiometry of the HTlc-DIC, that is, $\left[\mathrm{Mg}_{0.60} \mathrm{Al}_{0.40}(\mathrm{OH})_{2}\right] \mathrm{DIC}_{0.28}\left(\mathrm{NO}_{3}\right)_{0.12} \times 1.05 \mathrm{H}_{2} \mathrm{O}$. Considering the stoichiometric relations between HTlc and DIC in the above formula the amount of diclofenac is about $49 \%$ of the total hybrid weight.

Figure 1 also shows a comparison between TG curves of the pure spun PCL and the spun composite PCL-HDIC5, taken as representative of all the composites. The weight loss profiles of all composites are very similar each other being characterized by one important weight-loss stage, which occurs at midpoint of thermal degradation $(\mathrm{Td})$ values lower in comparison to that of the pure PCL which occurs at about $378^{\circ} \mathrm{C}$. The incorporation of the nanohybrid HTlc-DIC within PCL anticipates the Td midpoints of the composites, due to base-catalyzed hydrolysis on the ester bonds of filler constitution water, released during the thermal treatment, as described in a previous work [28]. The Td midpoints of the composites are, in fact, in the temperature range where the hybrids loose the constitution water with formation of the oxides, before the decomposition of the organic guests. These Td values slightly decrease on increasing the HTlc-DIC content up to $3 \mathrm{wt} \%$ and then remain quite constant over such value. For example, the Td value of the sample PCLHDIC5 is about $63^{\circ} \mathrm{C}$ lower than that of pure PCL, as shown in Table 2.

Table 2 shows some characterization thermal data of HTlc-DIC, the pristine PCL, and the composites thereby obtained.

3.2. Differential Scanning Calorimetry. To investigate the thermal behaviour, such as melting, crystallization, and formation of a crystalline structure, we performed DSC measurements. The heat flow DSC profiles for the nonisothermal 
TABLE 2: Thermogravimetric data extracted from the TGA curves of PCL, HTlc-DIC and PCL composites obtained by electrospinning.

\begin{tabular}{lccc}
\hline Sample & HTlc-DIC Content $(w t / w t-\%)$ & Diclofenac anion content $(w t \%)$ & Midpoint temperature $\left({ }^{\circ} \mathrm{C}\right)$ \\
\hline PCL & 0 & 0 & 378 \\
HTlc-DIC & 100 & 49 & 374 \\
PCL-HDIC1 & 1 & 0.49 & 334 \\
PCL-HDIC3 & 3 & 1.47 & 315 \\
PCL-HDIC5 & 5 & 2.45 & 315 \\
PCL-HDIC10 & 10 & 4.9 & 319 \\
\hline
\end{tabular}

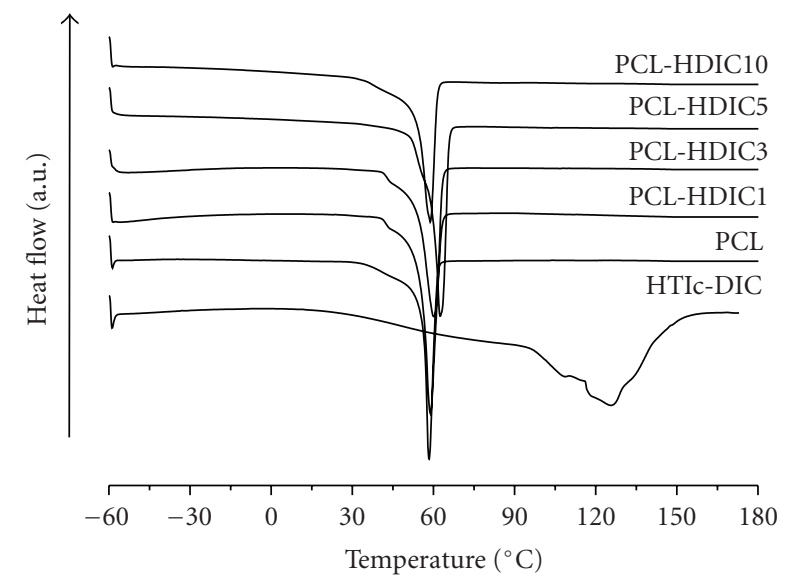

Figure 2: DSC heating scans of pure PCL, HTlc-DIC, PCL-HDIC1, PCL-HDIC3, PCL-HDIC5 and PCL-HDIC10.

melting behavior for pure PCL, the nanohybrid HTlc-DIC, and all PCL composites are represented in Figure 2.

The endothermic peak during the heating stage of pure PCL is centered at about $59^{\circ} \mathrm{C}$. This is attributed to the melting of the crystalline PCL phase.

The crystallinity degree $\left(X_{c}\right)$ of PCL and PCL component in the composites was evaluated by the melting peak area using the following equation (1):

$$
X_{c}=\frac{\Delta H_{m}}{\Delta H_{m}^{0} f},
$$

where $\Delta H_{m}^{0}$ is the heat of fusion for a theoretically $100 \%$ crystalline PCL (taken to be $146 \mathrm{~J} / \mathrm{g}$ [29]), $\Delta H_{m}$ is the melting enthalpy of the sample, and $f$ is the weight fraction of polymer.

As reported in Table 3, after incorporation of the nanohybrid HTlc-DIC in the PCL matrix, the melting temperatures $\left(T_{m}\right)$ shift moderately to higher values compared with pure PCL.

The melting enthalpy $\left(\Delta H_{m}\right)$ and the corresponding degree of crystallinity $\left(X_{c}\right)$ increase after incorporation of the nanohybrid. These results indicate that there are some interactions between PCL and HTlc-DIC; therefore the nanohybrid particles act as heterogeneous nucleation sites for PCL crystallization.

The presence of the inorganic nanohybrid decreases the degradation temperature of the matrix, without affecting its ability to crystallize and well organize.
TABLE 3: Calorimetric data extracted from the melting curves of PCL and PCL composites.

\begin{tabular}{lccc}
\hline Sample & $T_{m}\left({ }^{\circ} \mathrm{C}\right)$ & $\Delta H_{m}(\mathrm{~J} / \mathrm{g})$ & $X_{c}(\%)$ \\
\hline PCL & 58.67 & 75.61 & 51.79 \\
PCL-HDIC1 & 59.17 & 96.77 & 66.95 \\
PCL-HDIC3 & 60.17 & 86.15 & 60.83 \\
PCL-HDIC5 & 62.83 & 89.34 & 64.41 \\
PCL-HDIC10 & 59.00 & 73.78 & 56.15 \\
\hline
\end{tabular}

3.3. Powder X-Ray Diffraction. Information about the dispersion degree of the nanohybrids into PCL polymeric matrix was given by X-ray diffraction study. The powder XRD patterns of PCL, the nanohybrid HTlc-DIC, and relative composites obtained by electrospinning technique are shown in Figure 3.

The sharp peak at $3.86^{\circ}$ of $2 \theta$ of the pristine hydrotalcite HTlc-DIC indicates the formation of highly crystalline material. The basal spacing $\left(d_{003}\right)$ corresponds to an interlayer distance of $22.9 \AA$, due to the intercalation of diclofenac anions in the inorganic lamellae [26]. In the same figure the $\mathrm{X}$-ray diffractograms of pure PCL and the composites loaded with the inorganic nanohybrid component are shown.

The pure PCL, spun from the $15 \%$ solution in acetone, shows the crystalline structure well developed with the main peaks at $21.4^{\circ}$ and $23.8^{\circ}$ of $2 \theta$ and a reduced amorphous fraction.

The X-ray patterns of composites containing HTlc-DIC up to $3 \mathrm{wt} \%$ show only the typical reflections of crystalline PCL. This is an indication that the inorganic lamellae are well dispersed up to this concentration of HTlc-DIC. At variance at concentration of 5 and $10 \mathrm{wt} \%$ of HTlc-DIC the basal peak of the inorganic component is present in the diffractograms although of reduced intensity. This indicates that the inorganic lamellae neither exfoliated nor intercalated the polymer, giving rise to microcomposites. This effect, that is, the exfoliation up to a given concentration, and formation of microcomposites at higher values of concentration, has been already reported in many studies $[30,31]$.

3.4. Scanning Electron Microscopy (SEM). The morphology and the fiber diameters of the electrospun fibers have been investigated by Scanning Electronic Microscopy (SEM).

As reported in a previous study [32] PCL electrospun fibers without beads were obtained from acetone solution at concentration of $15 \mathrm{wt} \%$. 


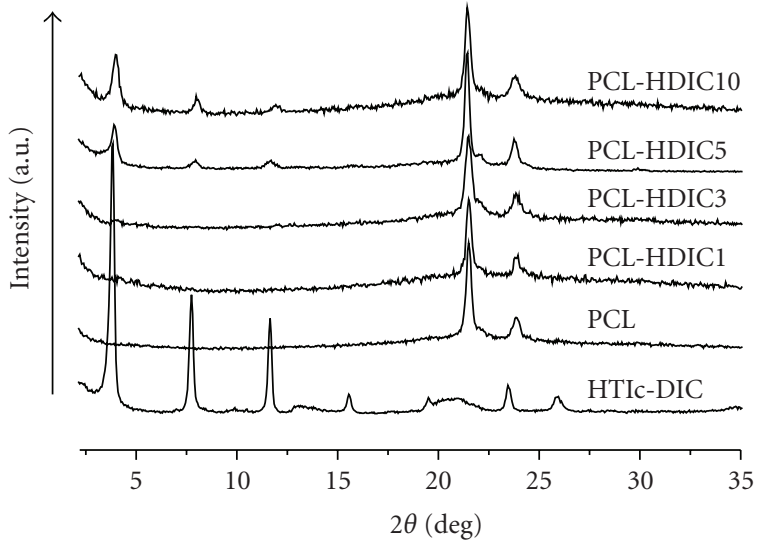

Figure 3: XRD patterns of: HTlc-DIC, PCL and PCL composites.

The SEM micrograph of electrospun PCL shown in Figure 4(a) revealed that the diameter of the PCL fibers in the nonwoven mat ranged from $500 \mathrm{~nm}$ to $3.0 \mu \mathrm{m}$. The individual electrospun fibers appear to be randomly distributed and generally had similar thickness along the fiber. About 100 fibers were tested in order to determine the diameter distribution.

The experimental conditions used to produce PCL fibers were also used to electrospin the composite samples (see experimental section). The addition of HTlc-DIC or DIC$\mathrm{Na}$ to PCL dissolved in acetone did not appear to hinder the electrospinning process. The fiber diameter morphology of the composite electrospun fibers was again examined using SEM. Based on the SEM micrographs for the different fibrous samples investigated, the fibers showed a similar fiber diameter and morphology to PCL fibers described above. For example, the PCL-HDIC5 fibers ranged between $500 \mathrm{~nm}$ and $3.0 \mu \mathrm{m}$ (average fiber diameter, $1.0 \mu \mathrm{m}$ ), with generally uniform thickness along the fibers. Again the electrospun fibers were distributed randomly in the nonwoven mat (see Figure 4(b)) with poor presence of beads.

The control sample, PCL-DICNa2.5, had similar fiber diameter characteristics of the composite with $5 \mathrm{wt} \%$ of HTlc-DIC: average $1.0 \mu \mathrm{m}$; maximum $2.5 \mu \mathrm{m}$; minimum $0.5 \mu \mathrm{m}$ (see Figure 4(c)).

It might be noted that the data are very similar in terms of diameter range for all samples, while the distribution is centred in a single value only for the composites. The introduction of DIC-Na or HTlc-DIC in the PCL creates fibers with similar distribution centred in $1.0 \mu \mathrm{m}$.

For the pure PCL and the control sample PCL-DICNa2.5 we observed the formation of fibers without beads; the sample PCL-HDIC5 has been electrospun in form of poorly beaded fibers.

On the basis of the x-ray diffraction and of the microscopy data it is possible to conclude that the interactions guest-host and guest-guest that occur inside the interlayer region of the filler could affect the dispersion degree and the exfoliation of the intercalation compounds into the polymer.
3.5. Diclofenac Release. The diclofenac release profiles from electrospun fibers of PCL-HDIC5 and the control sample PCL-DICNa2.5 are shown in Figure 5.

After 1 hour, less than $10 \mathrm{wt} \%$ of DIC was released from the composite PCL-HDIC5, whereas after the same time period it was completely released from the control sample PCL-DICNa2.5.

The release of diclofenac from the composite PCLHDIC5 is both much slower and more complex. Similar release kinetic curves were obtained for the other composites and for this reason only the data relative to the sample with $5 \mathrm{wt} \%$ of HTlc-DIC are shown. As can be seen in Figure 5, the sample PCL-HDIC5 presents a typical time-dependent profile with a fast release in an early period, followed by a very reduced release. The first step stage extends up to 1 hour and in this step $10 \%$ of the drug is released; the second stage, in which the released content of the drug is linearly dependent on the time, extends up to 4 days showing $20 \%$ of the drug released. The latter stage, followed up to 240 days, shows that only $50 \%$ of drug had been released for such a long time.

As in previous cases $[23,26]$ it can be suggested that the first stage is due to the drug anchored in the inorganic lamellae laying on the surface of the fibers. In this case the release time is dependent only on the ionic exchange reaction time, that is very rapid and is completed in 1 hour. The second and third stages are due to the drug coming from the inside of the matrix, whose exit depends on the diffusion behaviour of the counter-anion going in, the exchange reaction time, and on the diffusion of the drug itself going out. These three steps are very slow and a release extending for months can be observed.

The release rate of DIC anions from the nanohybrid is obviously lower than that from the physical mixture (PCL/DIC-Na). In addition, the release rate of DIC from the composites is dependent on DIC concentration in the sample. Increasing in drug load increases the extent of DIC release. Results of this study suggest the importance of diffusion through the LDH particle in controlling the drug release rate.

From the linear part of the kinetic curve (reported as $C_{t} / C_{\text {eq }}$ versus $\left.(t)^{1 / 2}\right)$, see Figure 6 , it is possible to calculate the diffusion coefficient $D\left(\mathrm{~cm}^{2} / \mathrm{s}\right)$ by the following equation (2) [33]:

$$
\frac{C_{t}}{C_{\mathrm{eq}}}=\frac{4}{d}\left(\frac{D t}{\pi}\right)^{1 / 2}
$$

where $C_{t}$ is the released concentration of DIC at time $t$, $C_{\mathrm{eq}}$ is the maximum equilibrium concentration of released molecules, and $d(\mathrm{~cm})$ is the thickness of the sample. Figure 6 reports $C_{t} / C_{\mathrm{eq}}$ versus square root of time for samples PCLDICNa2.5 (a) and PCL-HDIC5 (b).

Sample PCL-DICNa2.5 (Figure 6(a)) shows one step of diffusional behaviour giving a diffusion coefficient of $2.15 \times$ $10^{-9} \mathrm{~cm}^{2} / \mathrm{s}$. The $C_{t} / C_{\text {eq }}$ versus $(t)^{1 / 2}$ curve of sample PCLHDIC5 (Figure 6(b)) displays three steps of release from 

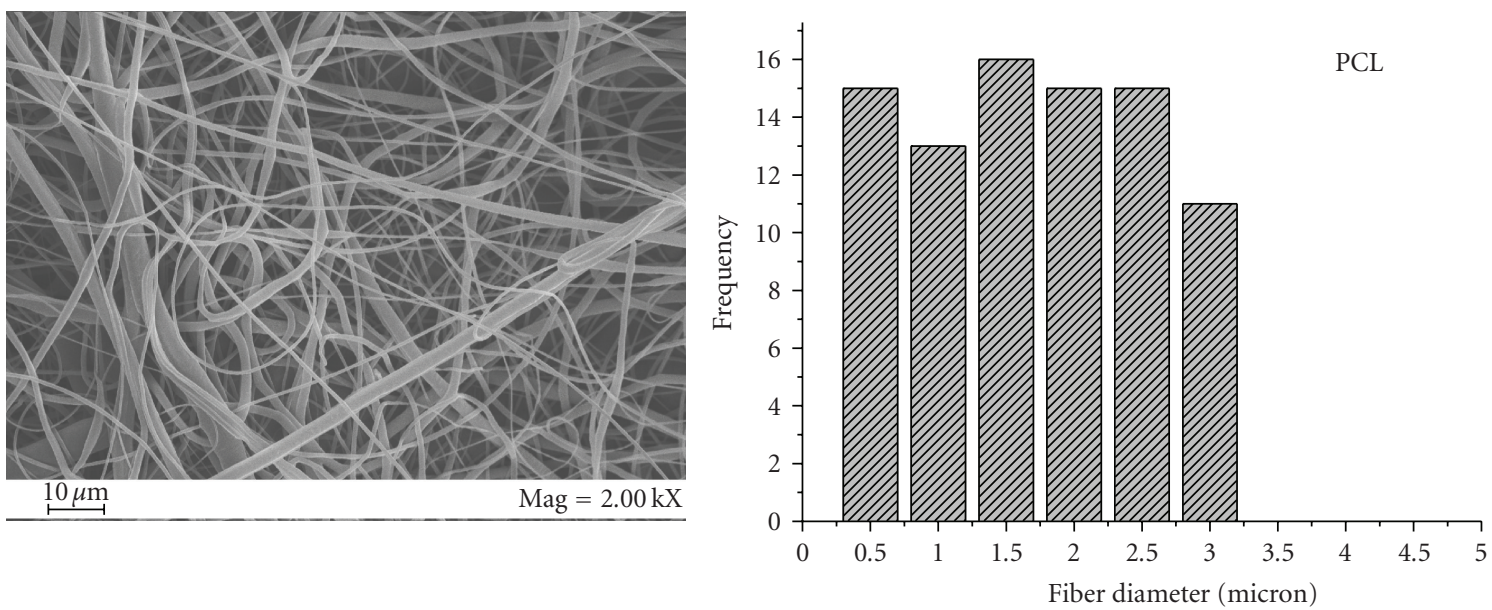

(a)
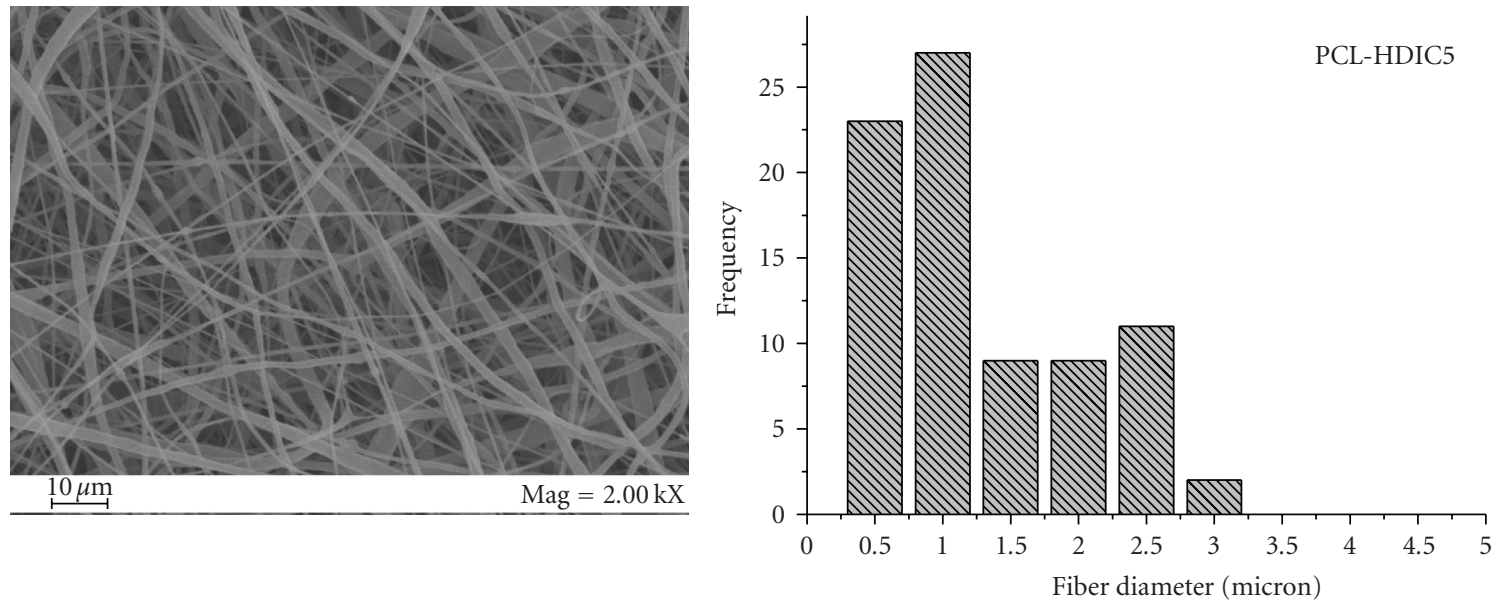

(b)
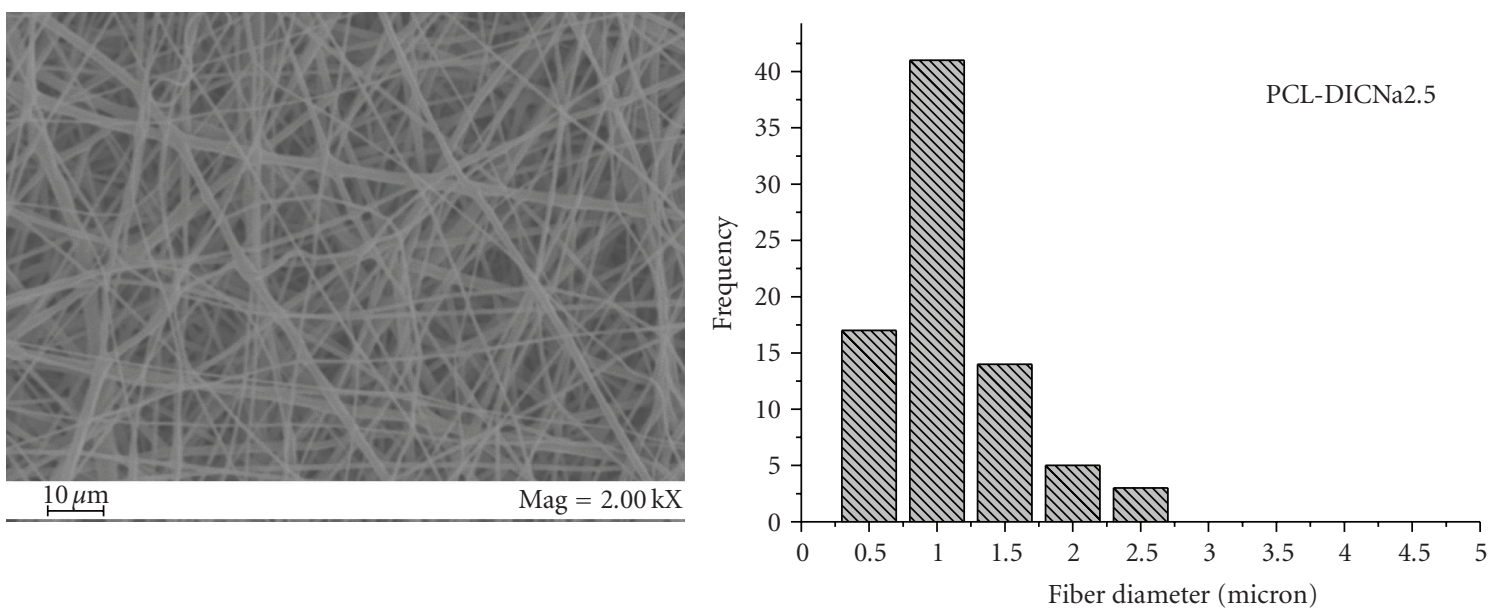

(c)

Figure 4: SEM micrographs and diameter distributions of pure PCL (a), PCL-HDIC5 (b) and PCL-DICNa2.5 (c) fibers, electrospun from $15 \mathrm{wt} \% \mathrm{PCL} /$ acetone solutions. 


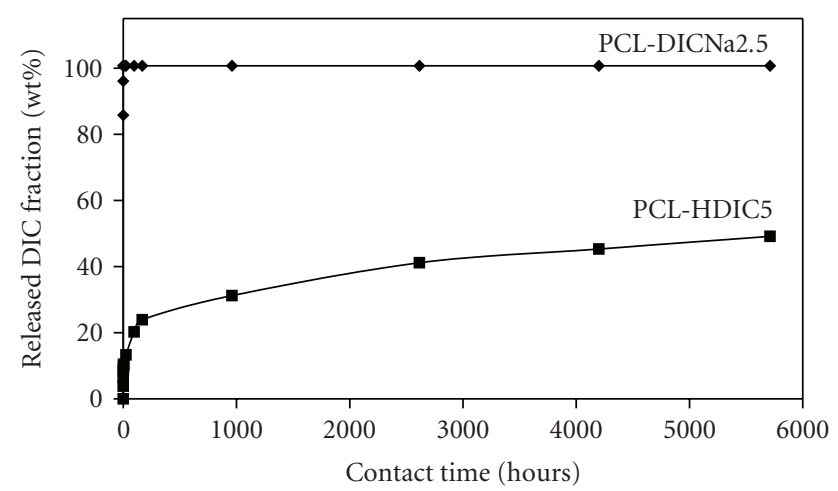

Figure 5: Release profiles of diclofenac from PCL-HDIC5 and PCLDICNa2.5 samples in physiological solution as a function of time.

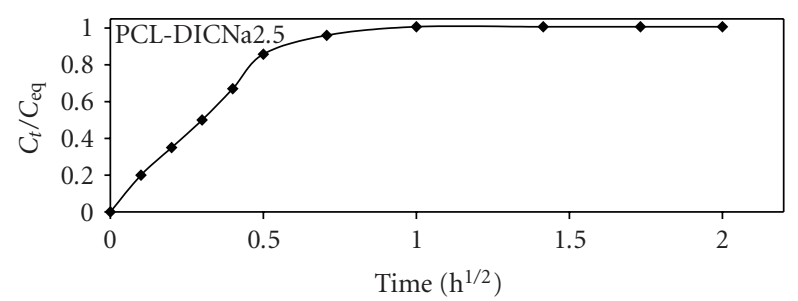

(a)

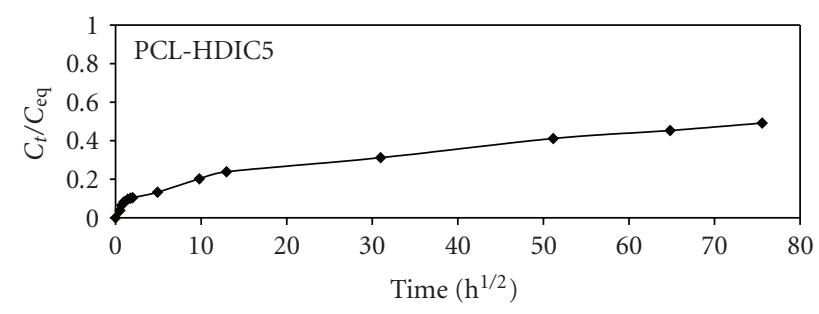

(b)

Figure 6: $C_{t} / C_{\mathrm{eq}}$ versus $(t)^{1 / 2}$ curves of PCL-DICNa2.5 (a) and PCL-HDIC5 (b). ( $C_{t}$ : diclofenac released concentration at time $t$ (hours); $C_{\mathrm{eq}}$ : maximum diclofenac equilibrium concentration; $d$ $(\mathrm{cm})$ : thickness of the sample).

which we calculated three different diffusion coefficients. The first step (up to 1 hour), corresponding to the time in which we observed the complete release of the active molecules from the sample PCL-DICNa2.5, shows a diffusion coefficient of $2.81 \times 10^{-11} \mathrm{~cm}^{2} / \mathrm{s}$. It is underlined that even in the rapid stage we obtained a very slow release of DIC, as demonstrated from $D$ value being two orders of magnitude lower than the control sample (PCL-DICNa2.5). The second step (from 1 to 96 hours) and the last step (from 4 to 240 days) show a much slower kinetics with an apparent diffusion coefficient of $6.16 \times 10^{-13} \mathrm{~cm}^{2} / \mathrm{s}$ and $6.62 \times 10^{-14} \mathrm{~cm}^{2} / \mathrm{s}$, respectively. The higher the contact time of samples with the physiological solution, is the lower is rate of DIC release.

\section{Concluding Remarks}

Microfibers of PCL and PCL composites with diameter less than $3.5 \mu \mathrm{m}$ have been successfully produced using the electrospinning process. The fibers were characterized by thermogravimetric analysis, differential scanning calorimetry, X-ray diffraction, and scanning electron microscopy. The drug release kinetics are remarkably lower than that from the corresponding control spun solutions of PCL and diclofenac sodium salt. On the basis of this study it can be concluded that electrospun PCL is a good matrix for containing and gradually releasing antinflammatory substance.

(i) The composites (PCL-HDICn) were obtained by mixing poly ( $\varepsilon$-caprolactone) (PCL) and a clay (Layered Double Hydroxide, LDH) modified with antiinflammatory molecules (diclofenac sodium) (HTlcDIC) in a wide range of concentration and then electrospun from acetone solution ( $15 \mathrm{wt} \%$ of PCL concentration).

(ii) The crystallinity and melting temperature of the composites resulted even higher than the pristine PCL, indicating a nucleant effect of the clay on the PCL crystallization.

(iii) X-ray diffraction showed a lack of the basal peak of clay at lower concentrations up to $3 \mathrm{wt} \%$ of HTlcDIC indicating a possible exfoliation of the clay. At higher concentration the presence of the basal peak indicated the formation of microcomposites.

(iv) The diameter of the pristine PCL and the composite samples observed by SEM indicated very similar values with a distribution centered at $1.0 \mu \mathrm{m}$ for the composites.

(v) The release of the diclofenac drug, investigated in the sample containing $5 \mathrm{wt} \%$ of HTlc-DIC, was found much slower than the release from the PCL sample containing the drug directly dispersed into the polymer fibers.

\section{References}

[1] A. R. Boccaccini and J. J. Blaker, "Bioactive composite materials for tissue engineering scaffolds," Expert Review of Medical Devices, vol. 2, no. 3, pp. 303-317, 2005.

[2] K. Zhang, Y. Wang, M. A. Hillmyer, and L. F. Francis, "Processing and properties of porous poly(L-lactide)/bioactive glass composites," Biomaterials, vol. 25, no. 13, pp. 2489-2500, 2004.

[3] A. R. Boccaccini, A. G. Stamboulis, A. Rashid, and J. A. Roether, "Composite surgical sutures with bioactive glass coating," Journal of Biomedical Materials Research B, vol. 67, no. 1, pp. 618-626, 2003.

[4] R. C. Thomson, M. J. Yaszemski, J. M. Powers, and A. G. Mikos, "Hydroxyapatite fiber reinforced poly ( $\alpha$-hydroxy ester) foams for bone regeneration," Biomaterials, vol. 19, no. 21, pp. 1935-1943, 1998.

[5] S. Yang, K.-F. Leong, Z. Du, and C.-K. Chua, "The design of scaffolds for use in tissue engineering. Part I. Traditional factors," Tissue Engineering, vol. 7, no. 6, pp. 679-689, 2001. 
[6] X. Liu and P. X. Ma, "Polymeric scaffolds for bone tissue engineering," Annals of Biomedical Engineering, vol. 32, no. 3, pp. 477-486, 2004.

[7] V. L. Tsang and S. N. Bhatia, "Three-dimensional tissue fabrication," Advanced Drug Delivery Reviews, vol. 56, no. 11, pp. 1635-1647, 2004.

[8] K. Rezwan, Q. Z. Chen, J. J. Blaker, and A. R. Boccaccini, "Biodegradable and bioactive porous polymer/inorganic composite scaffolds for bone tissue engineering," Biomaterials, vol. 27, no. 18, pp. 3413-3431, 2006.

[9] K.-H. Kim, L. Jeong, H.-N. Park, et al., "Biological efficacy of silk fibroin nanofiber membranes for guided bone regeneration," Journal of Biotechnology, vol. 120, no. 3, pp. 327-339, 2005.

[10] P. D. Dalton, K. Klinkhammer, J. Salber, D. Klee, and M. Möller, "Direct in vitro electrospinning with polymer melts," Biomacromolecules, vol. 7, no. 3, pp. 686-690, 2006.

[11] H. K. Noh, S. W. Lee, J.-M. Kim, et al., "Electrospinning of chitin nanofibers: degradation behavior and cellular response to normal human keratinocytes and fibroblasts," Biomaterials, vol. 27, no. 21, pp. 3934-3944, 2006.

[12] C. Li, C. Vepari, H.-J. Jin, H. J. Kim, and D. L. Kaplan, "Electrospun silk-BMP-2 scaffolds for bone tissue engineering," Biomaterials, vol. 27, no. 16, pp. 3115-3124, 2006.

[13] C. A. Bashur, L. A. Dahlgren, and A. S. Goldstein, "Effect of fiber diameter and orientation on fibroblast morphology and proliferation on electrospun poly(d,l-lactic-co-glycolic acid) meshes," Biomaterials, vol. 27, no. 33, pp. 5681-5688, 2006.

[14] W. E. Teo and S. Ramakrishna, "A review on electrospinning design and nanofiber assemblies," Nanotechnology, vol. 17, pp. R89-R106, 2006.

[15] Y. M. Shin, M. M. Hohman, M. P. Brenner, and G. C. Rutledge, "Electrospinning: a whipping fluid jet generates submicron polymer fibers," Applied Physics Letters, vol. 78, no. 8, pp. 1149-1151, 2001.

[16] J. M. Anderson and M. S. Shive, "Biodegradation and biocompatibility of PLA and PLGA microspheres," Advanced Drug Delivery Reviews, vol. 28, no. 1, pp. 5-24, 1997.

[17] J. S. Travis and A. R. Horst, "Electrospinning: applications in drug delivery and tissue engineering," Biomaterials, vol. 29, no. 13, pp. 1989-2006, 2008.

[18] S. Agarwal, J. H. Wendorff, and A. Greiner, "Use of electrospinning technique for biomedical applications," Polymer, vol. 49, no. 26, pp. 5603-5621, 2008.

[19] F. Trifirò and A. Vaccari, "Hydrotalcite anionic clays (layered double hydroxides)," in Solid-State Supramolecular Chemistry: Two and Three-dimensional Inorganic Networks of Comprehensive supramolecular Chemistry, G. Alberti and T. Bein, Eds., vol. 7, p. 251, Elsevier Science, Oxford, UK, 1996.

[20] V. Rives, Layered Double Hydroxides: Present and Future, Nova Science, New York, NY, USA, 2001.

[21] F. Leroux and C. Taviot-Guého, "Fine tuning between organic and inorganic host structure: new trends in layered double hydroxide hybrid assemblies," Journal of Materials Chemistry, vol. 15, no. 35-36, pp. 3628-3642, 2005.

[22] U. Costantino, V. Ambrogi, L. Perioli, and M. Nocchetti, "Hydrotalcite-like compounds: versatile layered hosts of molecular anions with biological activity," Microporous and Mesoporous Materials, vol. 107, no. 1-2, pp. 149-160, 2008.

[23] L. Tammaro, U. Costantino, A. Bolognese, et al., "Nanohybrids for controlled antibiotic release in topical applications," International Journal of Antimicrobial Agents, vol. 29, no. 4, pp. 417-423, 2007.
[24] L. Tammaro, U. Costantino, M. Nocchetti, and V. Vittoria, "Incorporation of active nano-hybrids into $\operatorname{poly}(\varepsilon-$ caprolactone) for local controlled release: antifibrinolytic drug," Applied Clay Science, vol. 43, no. 3-4, pp. 350-356, 2009.

[25] U. Costantino, F. Marmottini, M. Nocchetti, and R. Vivani, "New synthetic routes to hydrotalcite-like compoundscharacterisation and properties of the obtained materials," European Journal of Inorganic Chemistry, no. 10, pp. 14391446, 1998.

[26] G. Sammartino, G. Marenzi, L. Tammaro, et al., "Antiinflammatory drug incorporation into polymeric nanohybrids for local controlled release," International Journal of Immunopathology and Pharmacology, vol. 18, no. 3 Suppl, pp. 55-62, 2005.

[27] U. Costantino, F. Montanari, M. Nocchetti, F. Canepa, and A. Frache, "Preparation and characterisation of hydrotalcite/carboxyadamantane intercalation compounds as fillers of polymeric nanocomposites," Journal of Materials Chemistry, vol. 17, no. 11, pp. 1079-1086, 2007.

[28] U. Costantino, V. Bugatti, G. Gorrasi, et al., "New polymeric composites based on poly( $\varepsilon$-caprolactone) and layered double hydroxides containing antimicrobial species," ACS Applied Materials \& Interfaces, vol. 1, no. 3, pp. 668-677, 2009.

[29] B. Wunderlich, Macromolecular Physics, vol. 3, Academic Press, New York, NY, USA, 1980.

[30] R. Pucciariello, L. Tammaro, V. Villani, and V. Vittoria, "New nanohybrids of poly ( $\varepsilon$-caprolactone) and a modified $\mathrm{Mg} / \mathrm{Al}$ hydrotalcite: mechanical and thermal properties," Journal of Polymer Science B, vol. 45, no. 8, pp. 945-954, 2007.

[31] G. Gorrasi, M. Tortora, V. Vittoria, D. Kaempfer, and R. Mülhaupt, "Transport properties of organic vapors in nanocomposites of organophilic layered silicate and syndiotactic polypropylene," Polymer, vol. 44, no. 13, pp. 3679-3685, 2003.

[32] V. Romeo, G. Gorrasi, V. Vittoria, and I. S. Chronakis, "Encapsulation and exfoliation of inorganic lamellar fillers into polycaprolactone by electrospinning," Biomacromolecules, vol. 8, no. 10, pp. 3147-3152, 2007.

[33] W. R. Vieth and M. A. Amini, Permeability of Plastic Films and Coatings, vol. 6, Plenum Press, London, UK, 1974. 

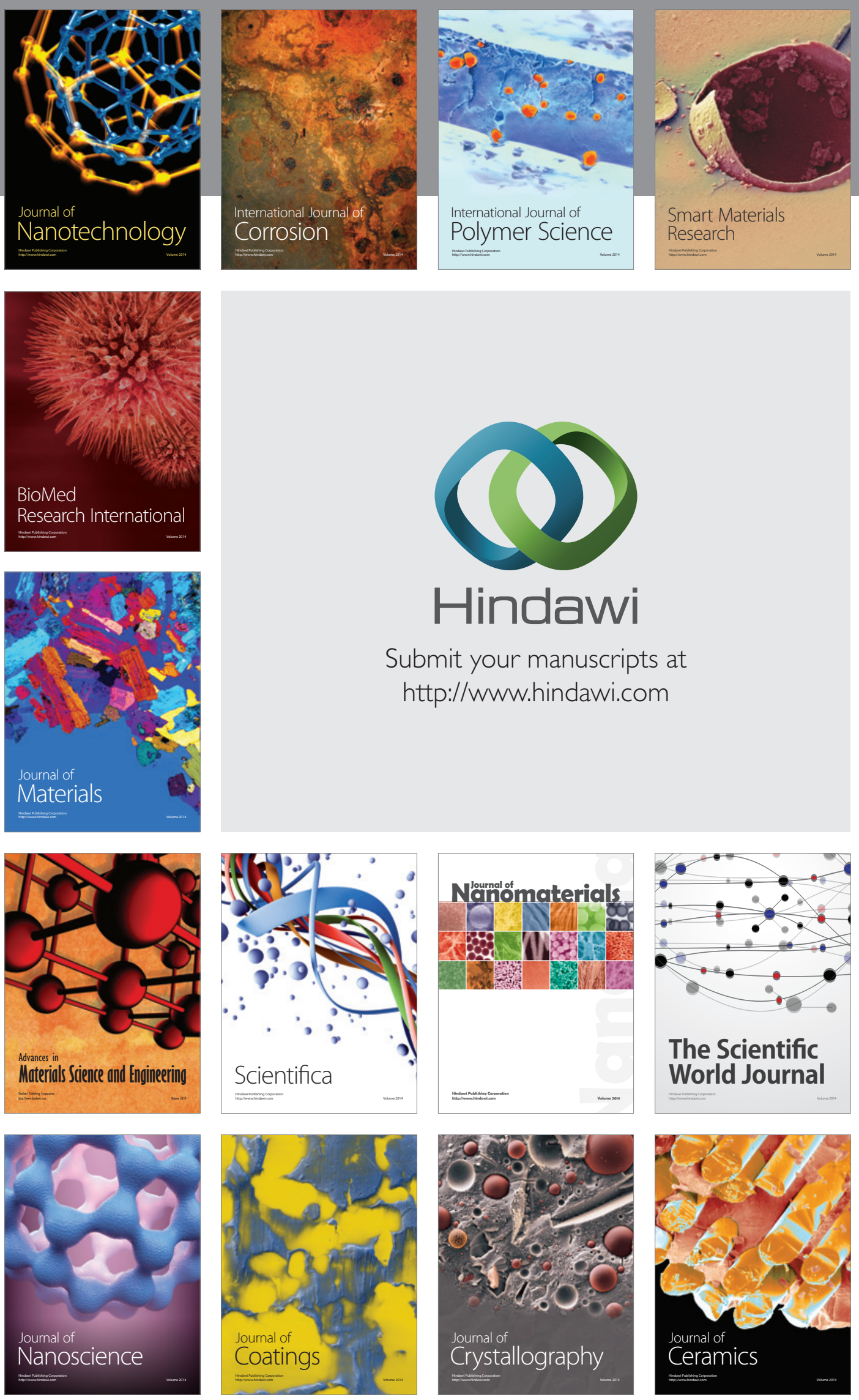

The Scientific World Journal

Submit your manuscripts at

http://www.hindawi.com

\section{World Journal}

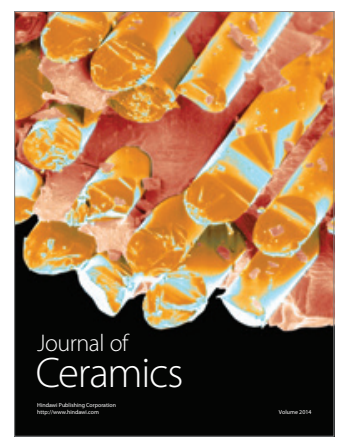

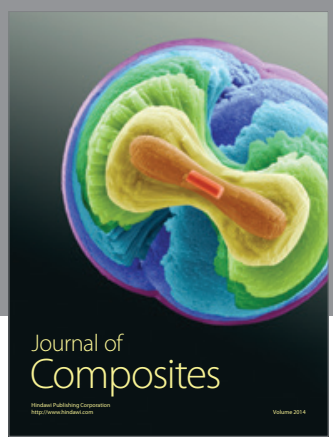
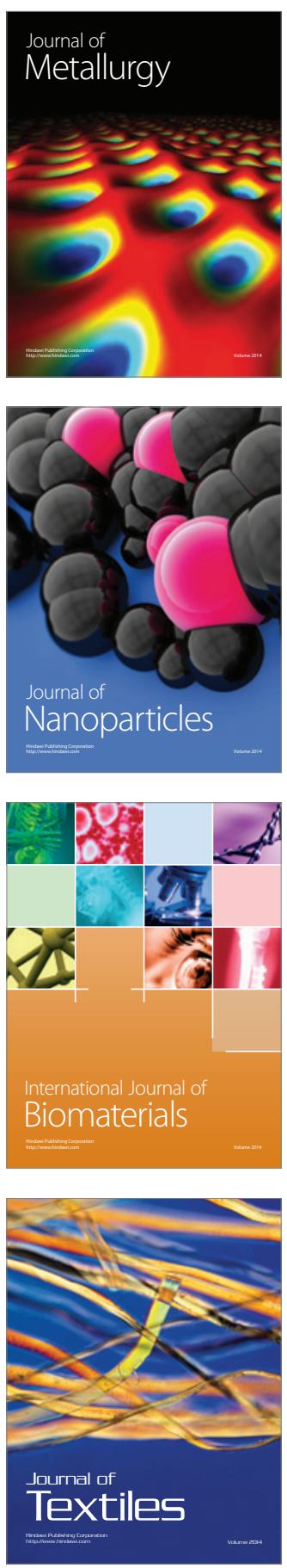